\title{
A Hybrid Humanoid-Wheeled Mobile Robotic Educational Platform - Design and Prototyping
}

\author{
Ali Haider Arif', 2, Muhammad Waqas', Ubaid ur Rahman', Sarosh Anwar', \\ Ahsan Malik ${ }^{1}$ and Jamshed Iqbal ${ }^{*}$ \\ 'Department of Electrical Engineering, COMSATS Institute of Information Technology (CIIT), Islamabad, Pakistan; \\ alihaiderarif@hotmail.com, vicky_dear007@yahoo.com, sh_ubaid@hotmail.com, sarosh18_92@yahoo.com, \\ ahsan_malik@comsats.edu.pk, jamshed.iqbal@comsats.edu.pk \\ ${ }^{2}$ Cielo WiGle Inc., Islamabad, Pakistan
}

\begin{abstract}
This research presents a novel, cost effective and indigenously developed educational framework for grasping hands-on concepts of Robotics and Mechatronics. The novelty of the platform lies in its ability to transform its shape from a humanoid to a wheeled mobile robot thus increasing the range of experiments that can be conducted using the proposed platform. The kinematics of the robot's legs is derived based on Denavit-Hartenberg (D-H) parameters while its 3D model is designed in CAD software. An aluminum-made DC servo actuated prototype consisting of 17 Degree Of Freedom (DOF) bipedal robot with four wheels is then fabricated. Preliminary experiments with the prototype including dynamically stable gait pattern and successful shape transformation and tentative list of experiments using the proposed framework demonstrate efficacy of the platform potentially useful for robotics community academicians, educationalists and hobbyists.
\end{abstract}

Keywords: Educational Platform, Humanoid Robot, Hybrid Mechanism, Wheeled Mobile Robot

\section{Introduction}

History of robotics dates back to 1920s. However, the last two decades witnessed technological as well as social revolution in this domain widening the spectrum of robot applications dramatically. Today, robots are being used actively in rehabilitation ${ }^{1-5}$, motion assistance ${ }^{6-9}$, cognition ${ }^{10,11}$, haptics/VR ${ }^{12}$ and target detection and tracking ${ }^{13,14}$ in addition to Nuclear Power Plants (NPP) ${ }^{15}$, Space ${ }^{16,17}$ and numerous other industrial applications $s^{18-20}$.

The domain of robotics, by definition is highly multi-disciplinary. It ranges in scope from the design of electrical and mechanical components to their control and computer systems to algorithms design. This makes it an extremely difficult task, particularly for a newbie, to fully understand the underlying principles of robotics thus highlighting an urge to have up-to-the-mark educational platforms. These platforms, when integrated with conventional theoretical lectures, facilitate students' learning by bridging the gap between theory and practice.
Engineering students who wish to commit themselves to robotics research find these educational frameworks beneficial for laying down firm foundations of the subject area. With these motivations, authors have realized educational platforms including AUTonomous Articulated Robotic Educational Platform (AUTAREP) ${ }^{21,22}$ and mobile robotic platforms ${ }^{23,24}$ for teaching various disciplines of robotics. Such frameworks are beneficial in dual fold; as academic tools, they reinforce engineering education and systematically compile knowledge that helps students and engineers to create innovative designs in their practical career while as research platforms, they can be used to test and validate various reported algorithms related with manipulators e.g. ${ }^{25-27}$ and mobile robots ${ }^{28-30}$.

The entrance of robotics in adolescence motivated scientists and researchers to explore new locomotion schemes for robots. Broadly categorizing, locomotion can be based on wheels, tracks and rigid links (as in legs and arms). Most of the today's robotics applications demand a robot to be mobile ${ }^{23}$. Recent advances in robotic home

${ }^{*}$ Author for correspondence 
appliances and personal robots suggest a paradigm shift from the industrial to the service sector ${ }^{31}$ thus making research on humanoids potentially beneficial and challenging. Though humanoids have rather limited capabilities, but have so far multitude of real world applications like technology demonstration, space missions, industrial platform, house hold helper, serving robot, war fields and much more. The most visible use of humanoid robot is technology demonstration ${ }^{32}$. Recent years witnessed particular interest in research on biped locomotion, structural, mechanism designs and Artificial Intelligence (AI) aspects of humanoids. It is anticipated that the role of humanoids to serve as assistants and companions for humans in normal routine life as well as in natural disasters will significantly increase in future.

The objective of this research is to propose an academic platform for teaching and training on humanoids. This paper is organized as follows: Section 2 presents literature review of the humanoid platforms with a tabulated comprehensive summary. Kinematic model of the robot's leg is derived in Section 3 while prototype design and fabrication is detailed in Section 4. Results and platform's specifications are presented in Section 5. Finally, Section 6 comments on conclusion.

\section{Related Work}

Scientific literature reports numerous humanoids developed by academia as well as industry. They vary widely in terms of design concept, Degree Of Freedom (DOF), physical dimensions and sensing capabilities.

Researchers at Waseda Univ., Japan were pioneer in presenting early-stage humanoids during late 1980s. WABIAN (WAseda BIpedal humANoid) $-2 \mathrm{R}^{33}$ is the latest robot in its series which has been developed as a human's partner and human motion simulator. Human like walking has been realized with a 3 DOF trunk motion and a 3-axis Zero Moment Point (ZMP) compensation using the trunk. The joints Range Of Motion (ROM) of the robot corresponds to human's one to mimic human movements. The robot can lean on a walk-assistance by controlling forearm. ASIMO (Advanced Step in Innovative Mobility) ${ }^{34}$ by Honda, released in 2000, is regarded as the world most advanced humanoid. The robot, designed to be a multi-functional mobile assistant, can execute high level planning and give rapid response based on vision and auditory systems. With the capability to climb stairs, the robot can change its direction while running. It can walk at $2.5 \mathrm{~km} / \mathrm{h}$ and also run at $3 \mathrm{~km} / \mathrm{h}$. Considering ASIMO as a benchmark, Korean researchers developed KHR-3 (KAIST Humanoid Robot ${ }^{35}$. Its physical parameters and number of DOF were similar to that of ASIMO. The robot, offering improved mechanical stiffness of links, can emulate human like movements like walking, somersaulting, climbing steps and doing back flips etc. The walking speed was limited to $1.25 \mathrm{~km} / \mathrm{h}$. iCub ${ }^{36}$ is an open source key research tool that resembles a 2.5 years old child. The robot, first released in 2008, has been developed with a focus to provide a world class testbed for research in humanoid, cognition and brain sciences. It has variety of sensors for hearing, seeing and touching. Distinguishing abilities of the platform include object grasping, crawling, avoiding collisions, solving complex mazes, expressing facial emotions and offering force based control. $\mathrm{NAO}^{37}$, another open-source platform, initially released in 2006, is considered as a star in the world of education. The platform is well known with reference to RoboCup, an international soccer competition. The robot's walking is based on a linear inverted pendulum dynamic model and quadratic programming. Other examples of humanoid platforms include HRP- ${ }^{38}$, ARMAR-III ${ }^{39}, \mathrm{H}^{40}$, PetMan $^{41}$ and Johnnie ${ }^{42}$.

Table 1 presents comparative review of the most popular humanoid platforms. These platforms are far beyond reach of many academic institutions primarily due to their extremely high cost. E.g. iCub is of more than 250000 Euros worth. Also, most of these platforms are not open source. Being sophisticated platforms, they may be well suited for professionals working in big research groups and industry, but for Undergraduate engineering students and hobbyists, a cost-effective, low weight and opensource platform having capabilities of humanoid as well as Wheeled Mobile Robot (WMR) would certainly be a more optimum choice. The present work attempts to meet this choice. Figure 1 illustrates 3D CAD model of the proposed platform. The wheels can be seen in Figure 1(b).

\section{Kinematic Model}

Given the joint angles of a robot, forward kinematics computes position and orientation of the end-effector. For a serial link robot, literature repots various kinematic modeling techniques ${ }^{43}$ including Denavit-Hartenberg (D-H) parameters, Hayati-Roberts (H-R) representation, screw theory, geometric based approaches etc. In this research, D-H parameters have been used to derive the legs kinematics owing to versatility, simplicity, and acceptability of this method to model any number of joints and links of serial manipulators despite of their 
Table 1. Comparative Summary of Humanoid Robots

\begin{tabular}{|c|c|c|c|c|c|c|c|}
\hline Robot & Developed by & Weight (Kg) & DOF & Height $(\mathrm{cm})$ & Sensors & Actuators & Ref. \\
\hline WABIAN-2R & $\begin{array}{l}\text { Waseda Univ., } \\
\text { Japan }\end{array}$ & 64 & 41 & 148.7 & $\begin{array}{l}\text { - } 6 \text { axis force/torque sensor } \\
\text { - Photo sensor } \\
\text { - Magnetic encoder } \\
\text { - Gyro sensor }\end{array}$ & - DC servo motors & [33] \\
\hline ASIMO & Honda & 50 & 34 & 130 & $\begin{array}{l}\text { - Gyroscope } \\
\text { - Accelerometer } \\
\text { - } 6 \text { axis Foot Area Sensor }\end{array}$ & $\begin{array}{l}\text { - DC servo motor } \\
\text { - Harmonic drive }\end{array}$ & [34] \\
\hline KHR-3 & KAIST, Korea & 55 & 41 & 125 & $\begin{array}{l}\text { - } 3 \text { axis F/T sensor } \\
\text { - Inclinometer } \\
\text { - Rate Gyro }\end{array}$ & $\begin{array}{l}\text { - DC servo motor } \\
\text { - Harmonic drive }\end{array}$ & [35] \\
\hline $\mathrm{iCub}$ & $\begin{array}{l}\text { Italian Inst. of Tech., } \\
\text { Italy }\end{array}$ & $23-25$ & 53 & 104 & $\begin{array}{l}\text { - Gyroscopes } \\
\text { - Accelerometers } \\
\text { - Encoders } \\
\text { - Force/torque sensors } \\
\text { - Capacitive tactile sensors } \\
\text { - Stereo Cameras } \\
\text { - Mic }\end{array}$ & $\begin{array}{l}\text { - Brushless motors } \\
\text { - DC motors }\end{array}$ & {$[36]$} \\
\hline $\mathrm{NAO}$ & $\begin{array}{l}\text { Aldebran Robotics, } \\
\text { France }\end{array}$ & 4.3 & $21-25$ & 58 & $\begin{array}{l}\text { - IMU } \\
\text { - FSR } \\
\text { - SONAR range finder } \\
\text { - Encoders } \\
\text { - IR RX/TX } \\
\text { - Capacitive tactile sensors } \\
\text { - Pressure sensors } \\
\text { - HD cameras } \\
\text { - Mic and speakers } \\
\text { - Bumpers }\end{array}$ & - Brush DC Coreless & {$[37]$} \\
\hline HRP-3 & $\begin{array}{l}\text { AIST, Kawada } \\
\text { Industries, Japan }\end{array}$ & 68 & 42 & 160.6 & $\begin{array}{l}\text { - } 3 \text { axes vibration gyro } \\
\text { - 3-axes velocity sensor } \\
\text { - Scanning range finder } \\
\text { - Stereo camera }\end{array}$ & $\begin{array}{l}\text { - DC servo motors } \\
\text { - Harmonic drive }\end{array}$ & {$[38]$} \\
\hline ARMAR-III & $\begin{array}{l}\text { Karlsruhe Inst. of } \\
\text { Tech., Germany }\end{array}$ & 135 & 43 & 175 & $\begin{array}{l}\text { - Motors encoders } \\
\text { - LRF } \\
\text { - 6D inertial sensor } \\
\text { - Axis sensors } \\
\text { - 6D force-torque sensor } \\
\text { - Dragonfly cameras } \\
\text { - Mic }\end{array}$ & $\begin{array}{l}\text { - DC motors } \\
\text { - Harmonic drives } \\
\text { - Fluidic actuators }\end{array}$ & {$[39]$} \\
\hline H6 & $\begin{array}{l}\text { Univ. of Tokyo, } \\
\text { Japan }\end{array}$ & 51 & 33 & 136 & $\begin{array}{l}\text { - Accelerometer } \\
\text { - Inclinometer } \\
\text { - FSR } \\
\text { - Pressure sensor } \\
\text { - Stereo cameras }\end{array}$ & $\begin{array}{l}\text { - DC motors } \\
\text { - Harmonic drive }\end{array}$ & {$[40]$} \\
\hline PetMan & Boston Dynamics & 80 & 27 (actuated) & 175 & $\begin{array}{l}\text { - IMU } \\
\text { - LIDAR } \\
\text { - Stereo cameras }\end{array}$ & $\begin{array}{l}\text { - Hydraulic } \\
\text { actuators }\end{array}$ & [41] \\
\hline Johnnie & $\begin{array}{l}\text { Tech. Univ. of } \\
\text { Munich, Germany }\end{array}$ & 40 & 17 & 180 & $\begin{array}{l}\text { - Incremental encoder } \\
\text { - Force sensors } \\
\text { - Gyroscopes } \\
\text { - Accelerometers }\end{array}$ & - Brush DC motors & {$[42]$} \\
\hline
\end{tabular}



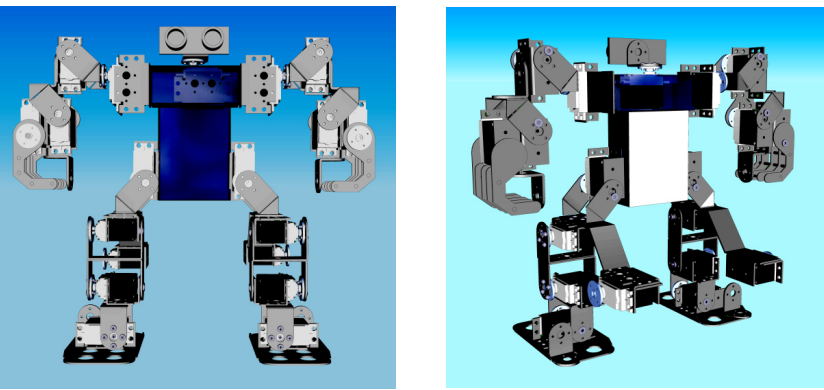

Figure 1. 3D CAD Model of the Proposed Platform (a) Front view (b) Back view

complexity ${ }^{44}$. D-H method considers each link as a rigid body where four parameters $\left\{a_{i-1}, a_{i-1}, d_{i}, \theta_{i}\right\}$ respectively represent twist angle, link length, link offset and joint angle ${ }^{45}$. For the sake of symmetry, only the kinematics of right leg is presented here. Attaching an orthonormal coordinate system to each link of the leg (Figure 2), D-H parameters obtained are tabulated in Table 2.

Expressing joint $i$ in its previous neighboring joint $i-1$, for each link of the leg, the corresponding transformation matrices have been written. Exploiting the compound transformation feature, the link matrices have been then

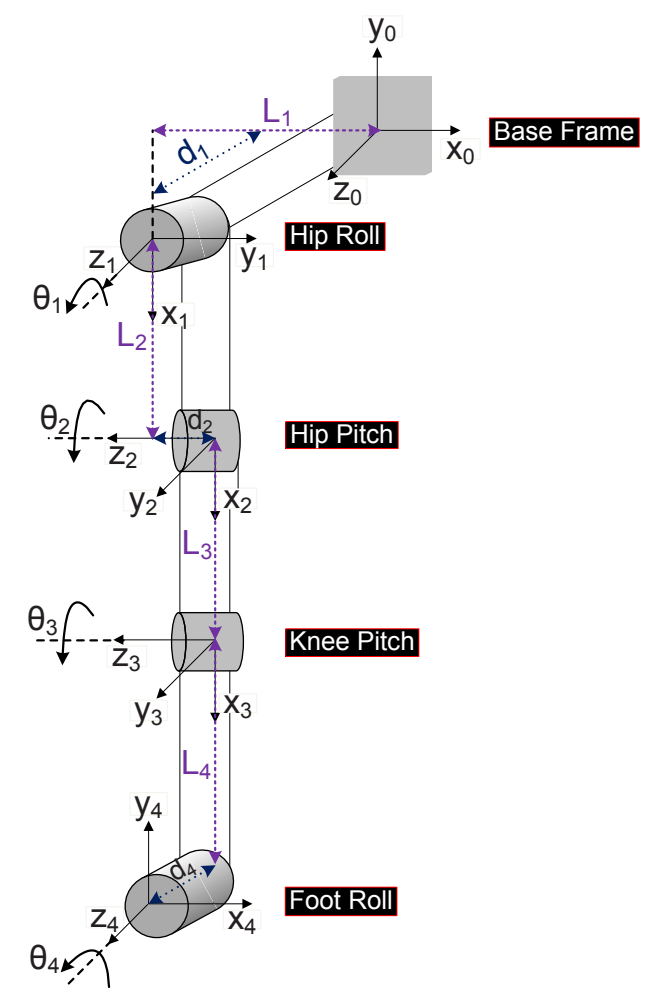

Figure 2. Right Leg Showing Joints and Frame Assignment
Table 2. DH Parameters of Right Leg

\begin{tabular}{ccccc}
\hline $\boldsymbol{I}$ & $\boldsymbol{a}_{\mathrm{i}-1}$ & $\mathrm{a}_{\mathrm{i}-1}$ & $\mathrm{~d}_{\mathrm{i}}$ & $\boldsymbol{\theta}_{\mathrm{i}}$ \\
\hline $\mathbf{1}$ & 0 & $\mathrm{~L}_{1}$ & $\mathrm{~d}_{1}$ & $\theta_{1}$ \\
$\mathbf{2}$ & $-90^{\circ}$ & $\mathrm{L}_{2}$ & $\mathrm{~d}_{2}$ & $\theta_{2}$ \\
$\mathbf{3}$ & 0 & $\mathrm{~L}_{3}$ & 0 & $\theta_{3}$ \\
$\mathbf{4}$ & $90^{\circ}$ & $\mathrm{L}_{4}$ & $\mathrm{~d}_{3}$ & $\theta_{4}$ \\
\hline
\end{tabular}

multiplied yielding an overall matrix that transforms end-effector coordinates into base of the robot.

$$
\underset{\text { End }}{\text { Base }} \mathrm{T}={ }_{4}^{0} \mathrm{~T}={ }_{1}^{0} \mathrm{~T}_{2}^{1} \mathrm{~T}_{3}^{2} \mathrm{~T}_{4}^{3} \mathrm{~T}
$$

$\begin{aligned}{ }_{4}^{0} \mathrm{~T} & =\left[\begin{array}{cccc}\cos \theta_{1} & -\sin \theta_{1} & 0 & \mathrm{~L}_{1} \\ \sin \theta_{1} & \cos \theta_{1} & 0 & 0 \\ 0 & 0 & 1 & \mathrm{~d}_{1} \\ 0 & 0 & 0 & 1\end{array}\right]\left[\begin{array}{cccc}\cos \theta_{2} & -\sin \theta_{2} & 0 & \mathrm{~L}_{2} \\ 0 & 0 & 1 & \mathrm{~d}_{2} \\ -\sin \theta_{2} & -\cos \theta_{2} & 0 & 0 \\ 0 & 0 & 0 & 1\end{array}\right] \\ & {\left[\begin{array}{cccc}\cos \theta_{3} & -\sin \theta_{3} & 0 & \mathrm{~L}_{3} \\ \sin \theta_{3} & \cos \theta_{3} & 0 & 0 \\ 0 & 0 & 1 & 0 \\ 0 & 0 & 0 & 1\end{array}\right]\left[\begin{array}{cccc}\cos \theta_{4} & -\sin \theta_{4} & 0 & \mathrm{~L}_{4} \\ 0 & 0 & -1 & -\mathrm{d}_{3} \\ \sin \theta_{4} & \cos \theta_{4} & 0 & 0 \\ 0 & 0 & 0 & 1\end{array}\right] }\end{aligned}$

Considering following nomenclature (symmetric for $\cos$ and $\sin )$,

$c_{a}=\cos (\mathrm{a})$

$c_{a b}=\cos (\mathrm{a}+\mathrm{b})=c_{a} c_{b}-s_{a} s_{b}$

The resultant transformation matrix can take the form of

$$
{ }_{4}^{0} \mathrm{~T}=\left[\begin{array}{cccc}
\mathrm{r}_{11} & \mathrm{r}_{12} & \mathrm{r}_{13} & \mathrm{p}_{\mathrm{x}} \\
\mathrm{r}_{21} & \mathrm{r}_{22} & \mathrm{r}_{23} & \mathrm{p}_{\mathrm{y}} \\
\mathrm{r}_{31} & \mathrm{r}_{32} & \mathrm{r}_{33} & \mathrm{p}_{\mathrm{z}} \\
0 & 0 & 0 & 1
\end{array}\right]
$$

where the coefficients are

$$
\begin{aligned}
& \mathrm{r}_{11}=c_{1} c_{4} c_{23}-s_{1} s_{4} \\
& \mathrm{r}_{12}=-c_{1} s_{4} c_{23}-s_{1} c_{4} \\
& \mathrm{r}_{13}=c_{1} s_{23} \\
& \mathrm{p}_{\mathrm{x}}=L_{1}+L_{2} c_{1}+L_{3} c_{1} c_{2}+L_{4} c_{1} c_{23}-d_{2} s_{1}+d_{3} c_{1} s_{23} \\
& \mathrm{r}_{21}=s_{1} c_{4} c_{23}+c_{1} s_{4} \\
& \mathrm{r}_{22}=-s_{1} s_{4} c_{23}+c_{1} c_{4} \\
& \mathrm{r}_{23}=s_{1} s_{23} \\
& \mathrm{p}_{\mathrm{y}}=L_{2} s_{1}+L_{3} s_{1} c_{2}+L_{4} s_{1} c_{23}+d_{2} c_{1}+d_{3} s_{1} s_{23} \\
& \mathrm{r}_{31}=-c_{4} s_{23} \\
& \mathrm{r}_{32}=s_{4} s_{23} \\
& \mathrm{r}_{33}=c_{23} \\
& \mathrm{p}_{\mathrm{z}}=-L_{3} s_{2}-L_{4} s_{23}+d_{1}+d_{3} c_{23}
\end{aligned}
$$


The $3 \times 3$ matrix in (1) comprising of first three rows and first three columns is the rotation while the last column $\left(\mathrm{p}_{\mathrm{x}}, \mathrm{p}_{\mathrm{y}}, \mathrm{p}_{z}\right)$ represents the position of end-effector w.r.t. base. The kinematics has been simulated using MATLAB ToolBox for Robotics ${ }^{46}$. A typical pose of right leg corresponding to joint angles $\left\{\theta_{1}, \theta_{2}, \theta_{3}, \theta_{4}\right\}$ as $\left\{0,90^{\circ}\right.$, $\left.90^{\circ}, 0\right\}$ is illustrated in Figure 3.

\section{Prototype Design and Fabrication}

The proposed platform has been prototyped in-house. Various phases of development and fabrication are presented here. The first prototype (Figure $4 \mathrm{a}$ ) having 6 DOF consisted of two legs without trunk. It was made from ice-cream sticks glued together. This prototype was made primarily to facilitate conceptual understanding of humanoid motion. The structure was weak since the sticks used to bend. The same structure was then fabricated in acrylic (Figure $4 \mathrm{~b}$ ). The prototype was strong though too heavy. The structure was capable of sliding since the robot could not lift its feet. For lighter and more optimum structure, the third prototype (Figure 4c) was fabricated in aluminum. This structure also lacked trunk. We used standard C, L and servo brackets joined firmly with nuts and bolts for fabricating the robot. This structure supported efficient walking. A trunk and dummy arms were then added exhibiting 12 DOF mechanism together with Ultrasonic ranging sensor for collision avoidance in the fourth prototype (Figure 4d).

The final prototype (Figure 5a) has $4 \mathrm{DOF} / \mathrm{leg}, 2$ DOF/arm, 2 DOF/hand and 1 DOF for head. Grippers are controlled with servo motors. To permit mechanism hybridization (Figure $5 \mathrm{~b}$ ), the biped robot is equipped with two motorized wheels and two free wheels. The active

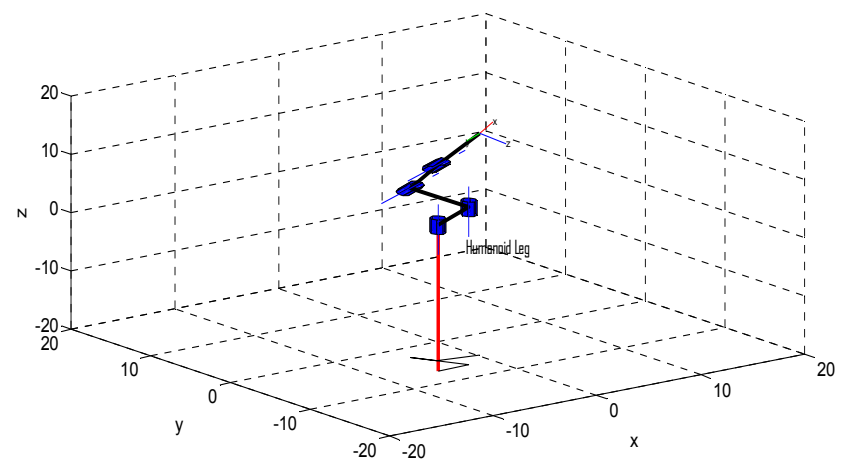

Figure 3. Simulated Leg at Typical Pose
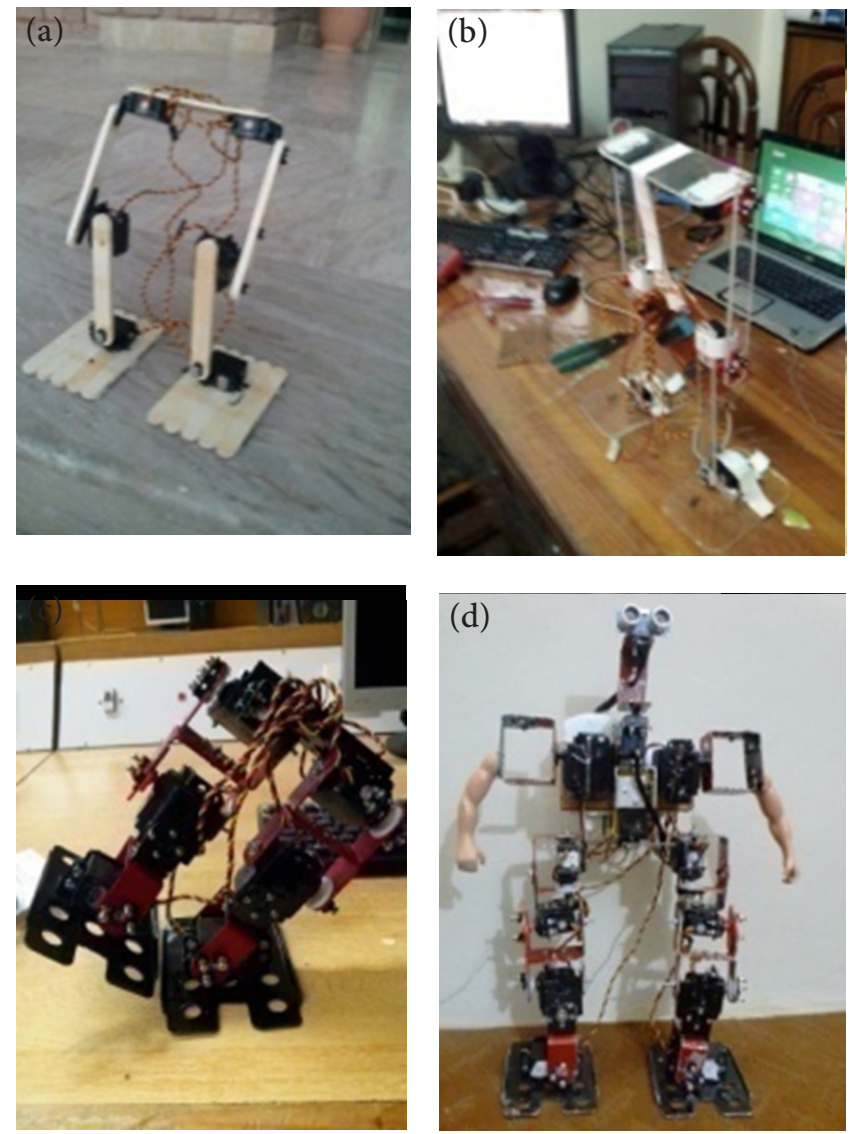

Figure 4. (a-d) Preliminary Prototypes Showing Design Phases.
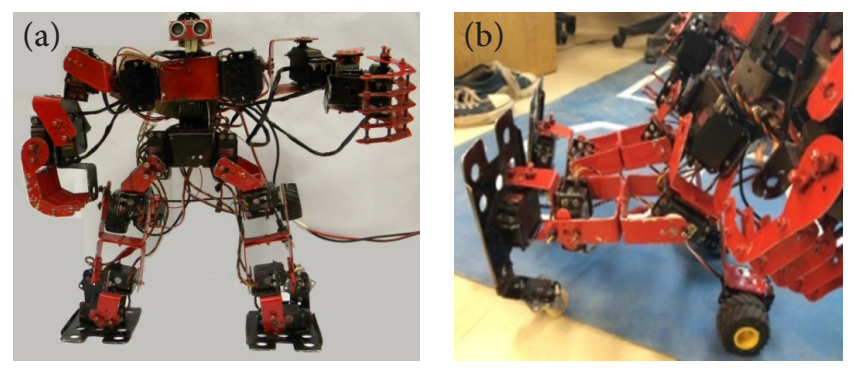

Figure 5. Final Prototype in: (a) Humanoid and (b) Wheeled Configuration.

wheels are driven by two dedicated continuous rotation servos. The embedded system is centered on two controllers working in Master-Slave configuration. Slave controller (Pololu-Mini Maestro 24-channel) drives the motors while Raspberry PI Model B intelligent controller acting as master interfaces Ultrasonic module and possible other visual sensors including camera. The on-robot Wi-Fi module permits off-site programming and remote operation. 


\section{Platform Specifications and Results}

The main specifications of the proposed hybrid platform are summarized in Table 3.

In order to verify the effectiveness of the proposed hybrid platform, two preliminary experiments have been carried out on a flat horizontal plane; walking and shape transformation. Figure $6(a-j)$ presents results of walking pattern while shape transformation is illustrated in (k-1). Initially, the robot is standing on the start line (a). For walking, it is tilted to left to shift Center of Gravity (CoG) (b). The left foot is first moved forward in air (c) and then placed back on ground (d). The robot tilts right with left foot placed ahead (e) followed by sliding and placing down the right foot as shown in (f)
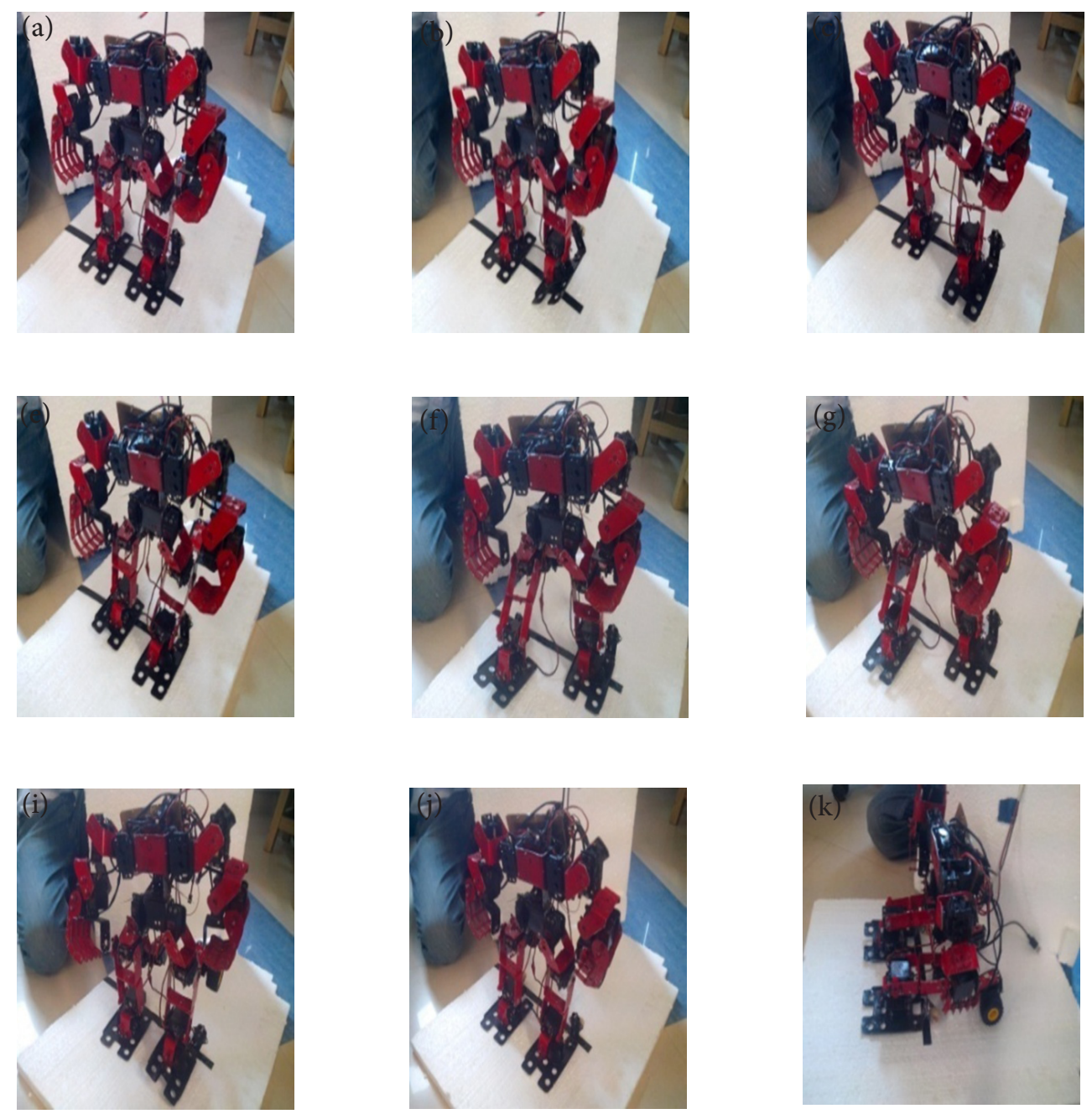
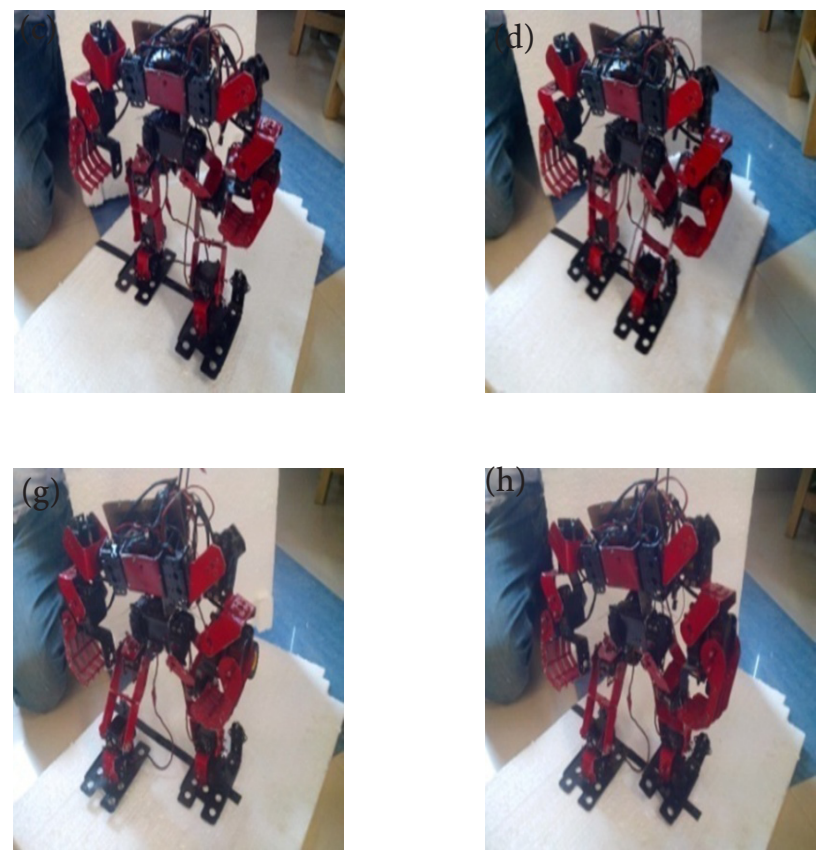

DC Servo motors (Qty: 19)

- 8 Hitec HS-645MG for Legs

- 9 Futaba S3003 for Torso

- 2 Spring SM-S4303R for Wheels

Sensors

Ultra Sonic (HC SR-04)

Operating System

Linux (Raspbian - Wheezy)

Programming Language Python

Connectivity

Wi-Fi, Ethernet

Figure 6. Pictorial Results of: (a-j) Robot Crossing the Line (k-1) Robot Transforming its Shape to Wheeled Configuration. 
Table 4. List of Experiments Using the Proposed Platform

\begin{tabular}{llc}
\hline Level & \multicolumn{1}{c}{ Title } & $\begin{array}{c}\text { Robot Configuration } \\
\mathrm{H} \text { - Humanoid } \\
\mathrm{W} \text { - Wheeled }\end{array}$ \\
\hline Basic & $\square$ Assembling a robotic mechanism & $\mathrm{H}+\mathrm{W}$ \\
& $\square$ Learn how to program a robot & $\mathrm{H}+\mathrm{W}$ \\
& $\square$ Generating PWM signals & $\mathrm{H}+\mathrm{W}$ \\
Intermediate & $\square$ DC servo motor control & $\mathrm{H}+\mathrm{W}$ \\
& $\square$ Walking on uniform surface & $\mathrm{H}+\mathrm{W}$ \\
Advanced & $\square$ Study the coupling effect b/w various joints of a robot & $\mathrm{H}$ \\
& $\square$ Analyzing walking algorithms on irregular terrains & $\mathrm{H}$ \\
& $\square$ Investigating balancing strategies & $\mathrm{W}$ \\
\hline
\end{tabular}

and $(\mathrm{g})$ respectively. It then tilts left to shift CoG (h) and subsequently moves the left foot forward (i) thus aligning both feet so as to cover distance of one step. The robot in $(j)$ is then commanded to transform its shape. Its knees are bend to $90^{\circ}(\mathrm{k})$ so that the rare wheels touch the ground. The knee joint again comes to $0^{\circ}(1)$ to shift frontage weight onto front casters. It is envisaged in near future to utilize advanced walking parameters like ZMP trajectory to realize an efficient walking scheme.

The proposed platform, owing to its diverse range of features, finds potential to practically demonstrate concepts related with mechatronics, control systems, algorithm design, system engineering, robot integration etc. A tentative list of laboratory experiments based on the platform for a beginner to an advanced user is given in Table 4.

\section{Acknowledgement}

This research has been funded by National Information \& Communication Technology (ICT) R\&D Fund under agreement no. NICTRFD/ NGIRI/ 2013-14/Corsp/1 Sr. 1.

\section{Conclusion}

A robotic platform of superior academic impact to practically demonstrate the relevant key concepts has been proposed in this paper. Primary distinguishing features of the presented framework include mechanism hybridization, design modularity, structural flexibility, use of inexpensive components and open architecture. The drawings, schematics, components lists and source codes are available for non-commercial use. Interested readers are requested to send an email to the corresponding author. Skipping licensing costs makes the framework a good source of academic learning. The presented list of experiments that can be conducted based on the proposed platform demonstrate its relevance with academic courses like robotics, control systems, mechatronics etc. Advanced users can tailor the platform by exploiting the open-source custom-developed hardware and software architectures. The modular design of the platform permits easy extension in terms of sensory system. e.g. adding an on-board camera allows conduction of computer vision related experiments.

\section{References}

1. Iqbal J, Khan AH, Tsagarakis NG, Caldwell DG. A novel exoskeleton robotic system for hand rehabilitation Conceptualization to prototyping. Biocybernetics and biomedical engineering. 2014; 34(2):79-89.

2. Iqbal J, Ahmad O, Malik A. HEXOSYS II - Towards realization of light mass robotics for the hand; Proceedings of 15th IEEE International Multitopic Conference (INMIC); 2011; Karachi, Pakistan. p. 115-9.

3. Iqbal J, Tsagarakis NG, Fiorilla AE, Caldwell DG. A portable rehabilitation device for the hand; Proceedings of 32nd annual IEEE international conference of Engineering in Medicine and Biology Society (EMBS); 2010; Buenos Aires, Argentina. p. 3694-7. 
4. Iqbal J, Tsagarakis NJ, Caldwell DG. A human hand compatible optimised exoskeleton system; Proceedings ofIEEE international conference on RObotics and BIOmimetics (ROBIO); 2010; China. p. 685-90.

5. Iqbal J, Tsagarakis NG, Caldwell DG. Design optimization of a hand exoskeleton rehabilitation device; Proceedings ofRSS workshop on understanding the human hand for advancing robotic manipulation; 2009; Seattle US. p. 44-5.

6. Iqbal J, Tsagarakis NG, Caldwell DG. Human hand compatible underactuated exoskeleton robotic system. IET electronic letters. 2014; 50(7):494-6.

7. Khan AA, Riaz S, Iqbal J. Surface estimation of a pedestrian walk for outdoor use of power wheelchair based robot. Life Sci J - Acta Zhengzhou University Overseas Edition. 2013; 10(3):1697-704.

8. Iqbal J, Tsagarakis NG, Caldwell DG. A multi-DOF robotic exoskeleton interface for hand motion assistance; Proceedings of 33rd annual IEEE international conference of Engineering in Medicine and Biology Society (EMBS); 2011; Boston, US. p. 1575-678.

9. Iqbal J, Tsagarakis NG, Fiorilla AE, Caldwell DG. Design requirements of a hand exoskeleton robotic device; Proceedings of 14th IASTED International Conference on Robotics and Applications (RA); 2009; Massachusetts US. p. $44-51$.

10. Naveed K, Iqbal J, Rahman H. Brain controlled human robot interface; Proceedings of IEEE International Conference on Robotics and Artificial Intelligence (ICRAI); 2012; Islamabad, Pakistan. p. 55-60.

11. Azeem MM, Iqbal J, Toivanen P, Samad A. Emotions in robots, Emerging Trends and Applications in Information Communication Technologies, Communications in Computer and Information Science (CCIS). SpringerVerlag Berlin Heidelberg; 2012.

12. Iqbal J, Tsagarakis NG, Caldwell DG. Design of a wearable direct-driven optimized hand exoskeleton device; Proceedings of 4th International Conference on Advances in Computer-Human Interactions (ACHI); 2011; France. p. 142-6.

13. Iqbal J, Pasha M, Riaz S, Khan H, Iqbal J. Real-time target detection and tracking: A comparative in-depth review of strategies.Life Sci J - Acta Zhengzhou University Overseas Edition. 2013; 10(3):804-13.

14. Iqbal J, Pasha SM, Khelifa B, Khan AA, Iqbal J. Computer vision inspired real-time autonomous moving target detection, tracking and locking. Life Sci J - Acta Zhengzhou University Overseas Edition. 2013; 10(4):3338-45.

15. Iqbal J, Tahir A, Islam RU, Nabi R. Robotics for nuclear power plants - Challenges and future perspectives; Proceedings of IEEE International Conference on Applied Robotics for the Power Industry (CARPI); Zurich, Switzerland; 2012. p. 151-6.
16. Iqbal J, Heikkila S, Halme A. Tether tracking and control of ROSA robotic rover; Proceedings of 10th IEEE International Conference on Control, Automation, Robotics and Vision (ICARCV); 2009; Vietnam. p. 689-93.

17. Iqbal J, Saad MR, Tahir AM, Malik A. State estimation technique for a planetary robotic rover. Revista Facultad de Ingenieria-Universidad de Antioquia. 2014;(In Press)

18. Islam RU, Iqbal J, Manzoor S, Khalid A, Khan S. An autonomous image-guided robotic system simulating industrial applications; Proceedings of 7 th IEEE International Conference on System of Systems Engineering (SoSE); 2012; Italy. p. 344-9.

19. Baizid K, Chellali R, Yousnadj R, Meddahi A, Iqbal J, Bentaleb T. Modelling of robotized site and simulation of robots optimum placement and orientation zone; Proceedings of 21st IASTED International Conference on Modelling and Simulation (MS); 2010; Canada. p. 9-16.

20. Meddahi A, Baizid K, Yousnadj A, Iqbal J. API based graphical simulation of robotized sites; Proceedings of14th IASTED International Conference on Robotics and Applications (RA); 2009; Massachusetts US. p. 485-92.

21. Manzoor S, Islam RU, Khalid A, Samad A, Iqbal J. An open-source multi-DOF articulated robotic educational platform for autonomous object manipulation.Robotics and Computer Integrated Manufacturing. 2014; 30(3):351-62.

22. Iqbal U, Samad A, Nissa Z, Iqbal J. Embedded control system for AUTAREP - A novel AUTonomous Articulated Robotic Educational Platform. Tehnicki Vjesnik-Technical Gazette.2014; 21(6):(In Press)

23. Iqbal J, Riaz S, Khan A, Khan H. A novel track-drive mobile robotic framework for conducting projects on robotics and control systems.Life Sci J - Acta Zhengzhou University Overseas Edition. 2013; 10(3):130-7.

24. Ahmad O, Ullah I, Iqbal J. A multi-robot educational and research framework. International Journal of Academic Research (IJAR) Part A. 2014; 6(2):217-22. ISSN: 2075-4124 (print), 2075-7107 (online).

25. Islam RU, Iqbal J, Khan Q. Design and comparison of two control strategies for multi-DOF articulated robotic arm manipulator. CEAI. 2014; 16(2):28-39.

26. Khan MF, Islam RU, Iqbal J. Control strategies for robotic manipulators; Proceedings ofIEEE International Conference on Robotics and Artificial Intelligence (ICRAI); 2012; Islamabad, Pakistan. p. 26-33.

27. Tavoosi J, Jokandan AS, Daneshwar MA. A new method for position control of a 2-DOF robot arm using neuro-fuzzy controller. Indian Journal of Science and Technology. 2012; 5(3):2253-7.

28. Zohaib M, Pasha SM, Javaid N, Salaam A, Iqbal J. An improved algorithm for collision avoidance in environments 
having U and H shaped obstacles. SIC. 2014; 23(1):97-106. ISSN: 1220-1766.

29. Jafri SR, Iqbal J, Khan H, Chellali R. A unified SLAM solution using partial 3D structure. Elektronika Ir Elektrotechnika (Journal of Electronics and Electrical Engineering). ISSN 1392-1215. (In Press)

30. Zohaib M, PashaSM, Bushra H, Hassan K, Iqbal J. Addressing collision avoidance and nonholonomic constraints of a wheeled robot: Modeling and simulation; Proceedings of IEEE International Conference on Robotics and Emerging Allied Technologies in Engineering (iCREATE); 2014; p. 306-11.

31. Bruno S, Oussama K. Handbook of Robotics. Springer; 2008.

32. Behnke, Sven. Humanoid Robots-From Fiction to Reality?. 2008;22(4):5-9.

33. Ogura Y, Aikawa H, Shimomura K, Kondo H, Morishima A, Lim H, Takanishi A. Development of a New Humanoid Robot WABIAN-2; Proceedings of IEEE International Conference on Robotics and Automation (ICRA); 2006; p. $76-81$.

34. Sakagami, Yoshiaki, Watanabe R, Aoyama C, Matsunaga S, Higaki N, Fujimura K. The intelligent ASIMO: System overview and integration. Proceedings of Intelligent Robots and Systems IEEE; 2002; 2478-83.

35. Park, Ill-Woo, Kim J, Lee J, Oh J. Mechanical design of humanoid robot platform KHR-3 (KAIST humanoid robot 3: HUBO). Proceedings of 5th IEEE-RAS International Conference on Humanoid Robots; 2005; 321-6.

36. Tsagarakis, Nikolaos G, Metta G, Sandini G, Vernon D, Beira R, Becchi F, LudovicRighetti et al. iCub: the design and realization of an open humanoid platform for cognitive and neuroscience research. Advanced Robotics. 2007; 21(10):1151-75.

37. Gouaillier D, Hugel V, Blazevic P, Kilner C, Monceaux J, Lafourcade P, Marnier B, Serre J, Maisonnier B. Mechatronic design of NAO humanoid. Proceedings ofIEEE International
Conference on Robotics and Automation; 2009; Kobe, Japan.

38. Kaneko K, Harada K, Kanehiro F, Miyamori G, Akachi K. Humanoid robot hrp-3. Proceedings of IEEE/RSJ International Conference on Intelligent Robots and Systems; 2008; 2471-8.

39. Asfour T, Do M, Welke K, Bierbaum A, Azad P, Vahrenkamp N, Gartner S, Ude A, Dillmann R. Sensorimotor Primitives to Manipulation and Imitation Strategies in Humanoid Robots, Pradalier C, Siegwart R, and Hirzinger G.Robotics Research, STAR 70.SpringerVerlag Berlin Heidelberg; 2011.

40. Nishiwaki K, Sugihara T, Kagami S, Kanehiro F, Inaba M, Inoue H. Design and Development of Research Platform for Perception Action Integration in Humanoid Robot: H6. Preceedings of IEEE/RSJ Int. Conference on Intelligent Robots and Systems; 2000; 1559-64.

41. Boston Dynamics Inc. [Internet]. [cited 2014 July 10]. Available from http://www.bostondynamics.com/robot_ petman.html

42. Löffler K, Gienger M, Pfeiffer F. Sensor and Control Design of a Dynamically Stable Biped Robot. Preceedings of IEEE Int. Conference on Robotics and Automation; 2003; p. $484-90$.

43. Iqbal J, Islam RU, Khan AH. Modeling and analysis of a 6 DOF robotic arm manipulator. CJEEE. 2012; 3(6):300-6. ISSN: 1923-0540.

44. Ullah MI, Ajwad SA, Islam R, Iqbal U, Iqbal J. Modeling and computed torque control of a 6 Degree of Freedom robotic arm. Proceedings of IEEE International Conference on Robotics and Emerging Allied Technologies in Engineering (iCREATE); p. 133-8.

45. Craig JJ. Introduction to Robotics: Mechanics and Control. 2004

46. Corke P. Robotics, vision and control: Fundamental algorithms in MATLAB. Springer; 2011. 